\title{
Magnetic and Electromagnetic signals related to tectonic activity: updates and new analyses on measurements in Central Italy
}

\author{
D. Di Mauro, S. Lepidi, A. Meloni, and P. Palangio \\ Istituto Nazionale di Geofisica e Vulcanologia, Rome, Italy \\ Received: 4 July 2005 - Revised: 22 September 2005 - Accepted: 22 September 2005 - Published: 22 November 2005 \\ Part of Special Issue "Seismic hazard evaluation, precursory phenomena and seismo electromagnetics"
}

\begin{abstract}
Tectonomagnetic field observations from absolute magnetic field levels have been collected in Central Italy since 1989 by means of a network of four absolute magnetometer stations, including the geomagnetic observatory of L'Aquila $\left(42^{\circ} 23 \mathrm{~N}, 13^{\circ} 19 \mathrm{E}\right)$ used as reference for differentiation; also electromagnetic variations from VLF signals have been recorded in the last years by means of VLF search coil wide-band antennas.

Many reports proved the occurrence of electromagnetic effects clearly related to tectonic events (seismic and volcanic activity) in active areas of our planet. In this paper we show the variation of some electromagnetic parameters which could be related to local and regional seismic activity for the most recent years 2002 and 2003. We also report the seismic activity recorded in this area by the Italian seismic national network.

Some tentative analysis (in the wavelets and statistical approach) on the historical and recent dataset allow a better characterization of electromagnetic properties of the study area, at different temporal and spatial scales.
\end{abstract}

\section{Introduction}

Several studies related ground-based observations of electromagnetic variations, over a very wide frequency range, to tectonic events, such as earthquakes or volcanic eruptions (see for example the monograph by Hayakawa and Fujinawa, 1994, and the review by Johnston, 1997). In this paper we focus in particular on observations of tectonomagnetic field and natural VLF waves (Parrot and Johnston, 1993; Meloni et al., 2001; Hayakawa and Molchanov, 2002).

Tectonomagnetic field observations are measurements of the Earth's magnetic field slow time variations related to changes of the physical properties of the uppermost crustal materials in association with tectonic activity; these changes

Correspondence to: S. Lepidi

(lepidi@ingv.it) are generally attributed to piezomagnetic and electrokinetic effects, assuming that rocks change their magnetization under stress or thermal solicitations and under variation of concentration gradients of electrolytes and flow of pore fluids in fractured rocks. All these mechanisms are strongly supported by laboratory tests, and at present, variations of few nT have been claimed by observers, both in the case of earthquake and volcanic events (see for example: Johnston, 1997, 2002; Del Negro and Currenti, 2003). Electromagnetic field emissions at low frequencies can be generally attributed to piezoelectric effects or charge redistributions.

Also higher frequency electromagnetic phenomena associated with earthquakes have been extensively studied in recent years. In this paper we refer to measurements in the VLF band only; in this frequency band, electromagnetic signals can be generated by various natural and artificial sources, the most significant source being related to lightning discharges (see the review by Barr et al., 2000). VLF waves travel within the Earth-ionosphere wave guide, reflected by the lowest ionospheric region (the D-region during daytime and the E-region at night); in this sense, VLF phenomena can provide useful information on ionospheric conditions. Several studies have analysed VLF radio transmitted signals and reported perturbations of phase and amplitude in association with earthquakes (Gokhberg et al., 1989; Hayakawa and Fujinawa, 1994; Morgounov et al., 1994; Parrot, 1995; Nagao et al., 2002; Shvets et al., 2004). Another physical quantity that provides information on ionospheric long-term changes is the terminator time (TT), i.e. the time of the daily variation of VLF signals in the morning and evening, related to sunrise and sunset, respectively; recent studies have shown deviations of the TT (a decrease in the morning and an increase in the afternoon) which appear some days before large earthquakes and disappear a few days after (Hayakawa et al., 1996 a, b; Molchanov and Hayakawa, 1998; Molchanov et al., 1998; Rozhnoi et al., 2004); the observed features could be explained in terms of a drop in the VLF reflection height by a few kilometres. 
Table 1. List and geographic location of earthquakes with $M d \geq 4.0$ occurred in the target area of Central Italy during 2002 and 2003 . Source: INGV Seismic Bulletin (2004).

\begin{tabular}{|c|c|c|c|}
\hline Date and time & Mag. $M d$ & Lat., Long. & Marks \\
\hline 01 June 2003 15:45:17 & 4.2 & 41.6814 .80 & Campobasso Eq. \\
\hline 01 June 2003 01:46:00 & 4.0 & 43.1915 .43 & \\
\hline 05 May 2003 06:16:00 & 4.2 & 43.1315 .38 & \\
\hline 02 May 2003 03:53:07 & 4.0 & 41.7314 .82 & Campobasso Eq. \\
\hline 26 April 2003 08:21:00 & 4.1 & 43.2015 .45 & Adriatic sea sequence \\
\hline 31 March 2003 19:36:28 & 4.3 & 43.0915 .38 & $"$ \\
\hline 30 March 2003 11:10:00 & 4.4 & 43.1015 .40 & $"$ \\
\hline 30 March 2003 00:56:22 & 4.0 & 43.1915 .43 & $"$ \\
\hline 29 March 2003 17:42:00 & 5.4 & 43.1315 .41 & $"$ \\
\hline 27 March 2003 16:14:00 & 4.0 & 43.2015 .49 & $"$ \\
\hline 27 March 2003 16:10:00 & 4.7 & 43.2015 .49 & $"$ \\
\hline 12 November 2002 09:27:48 & 4.2 & 41.6814 .79 & Molise Eq. and sequence \\
\hline 04 November 2002 03:26:00 & 4.1 & 41.7314 .80 & $"$ \\
\hline 04 November 2002 00:35:00 & 4.2 & 41.6714 .82 & $"$ \\
\hline 01 November 2002 17:21:00 & 4.3 & 41.7114 .82 & $"$ \\
\hline 01 November 2002 15:20:00 & 4.1 & 41.7414 .85 & $"$ \\
\hline 01 November 2002 15:08:00 & 5.3 & 41.6914 .83 & $"$ \\
\hline 31 October 2002 10:32:00 & 5.4 & 41.7614 .94 & $"$ \\
\hline 18 April 2002 20:56:00 & 4.1 & 40.6515 .58 & Potenza earthquake \\
\hline
\end{tabular}

This work follows previous papers concerning tectonomagnetic and VLF observations in Central Italy (Meloni et al., 2001, 2004; Di Mauro et al., 2005 ${ }^{1}$ ).

We show the whole dataset of tectnonomagnetic observations, which covers about fourteen years, with a particular attention to 2002 and 2003; in particular, we analyze the absolute magnetic field variations measured by means of a network of magnetometers, whose data are differentiated with respect to the Italian magnetic observatory of L'Aquila $\left(42^{\circ} 23 \mathrm{~N}, 13^{\circ} 19 \mathrm{E}\right)$, used as reference to reject non local variations on the dataset.

We also analyze VLF signals recorded in L'Aquila by means of VLF search coil wide-band antennas, working in two different frequency bands; in this case, the data set covers periods of several months during the last years.

We also report on seismic activity recorded in the area by the seismic national network during 2002 and 2003 and show some tentative correlation between tectonomagnetic and VLF signals and local and regional seismic activity.

\section{The network and instrumentation}

In Central Italy, in the area between latitudes $41^{\circ} \mathrm{N}$ and $43^{\circ} \mathrm{N}$ and longitudes $12^{\circ} \mathrm{E}$ and $15^{\circ} \mathrm{E}$, magnetic signals possibly related to earthquake occurrence are monitored by means of a network of four stations, including the national geomagnetic observatory of L'Aquila; the location of the stations,

\footnotetext{
${ }^{1}$ Di Mauro, D., Lepidi, S., Meloni, A., and Palangio, P.: Update on monitoring of magnetic and electromagnetic tectonic signals in Central Italy, Annals of Geophysics, submitted, 2005.
}

together with their acronyms, is shown in Fig. 1. At each station the total magnetic field intensity is recorded by means of a proton procession magnetometer, with a sampling rate of $15 \mathrm{~min}$. Measured values are averaged and differentiated with respect to L'Aquila geomagnetic observatory data, in order to filter out contributions from external sources, from regional inhomogeneities of the Earth's magnetic field and long term contributions of internal origin. The seismomagnetic stations are operating since 1989, with some data lacks due to instrumental failures; due to a technical problem, in August 2002 data acquisition at RIT station was interrupted.

In the last years, natural signals in VLF band are monitored in L'Aquila observatory by means of two search coil wide band antennas, operating in the range $15-40 \mathrm{kHz}$. The system measures the signal RMS integrated over two frequency bands, centered at 20 and $40 \mathrm{kHz}$, respectively. Radiometer sensitivity is $200 \mathrm{fT}$ at $40 \mathrm{~Hz}$ and data are sampled at $1 \mathrm{~Hz}$ frequency, and stored at $1 \mathrm{~min}$, with a 16 bit resolution, after averaging 60 values each. The area surrounding the observatory is characterized by a low level of local artificial electromagnetic noise; in the frequency band of interest, we receive radio signals from several VLF radio stations. The VLF data time periods with a better data coverage are March-September 2001 and August 2002-March 2003 (this last data set is continuous for 220 consecutive days).

Central Italy is a seismically active area, with earthquakes mainly occurring along the NW-SE axis of the Apennine mountain belt. Events occurred in recent years, like the Molise sequence with magnitude up to $M d=5.4$ in OctoberNovember 2002 and the Adriatic sea sequence, also with magnitude up to $M d=5.4$, in March 2003. In Table 1 all 


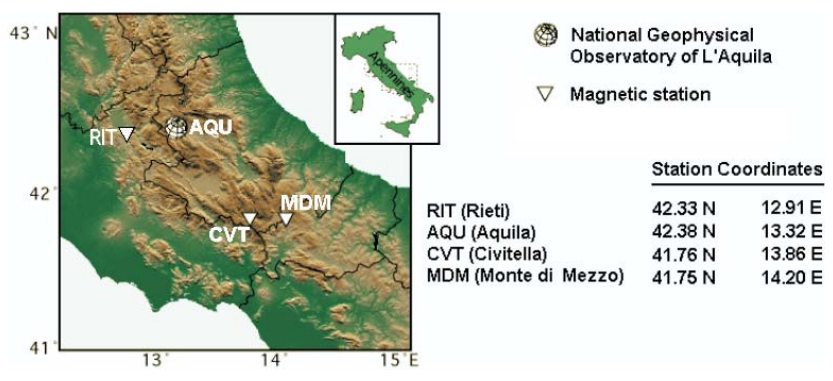

Fig. 1. Map of target area with location and geographic coordinates of the magnetometer stations MDM, CVT, RIT and the national geomagnetic observatory of L'Aquila.

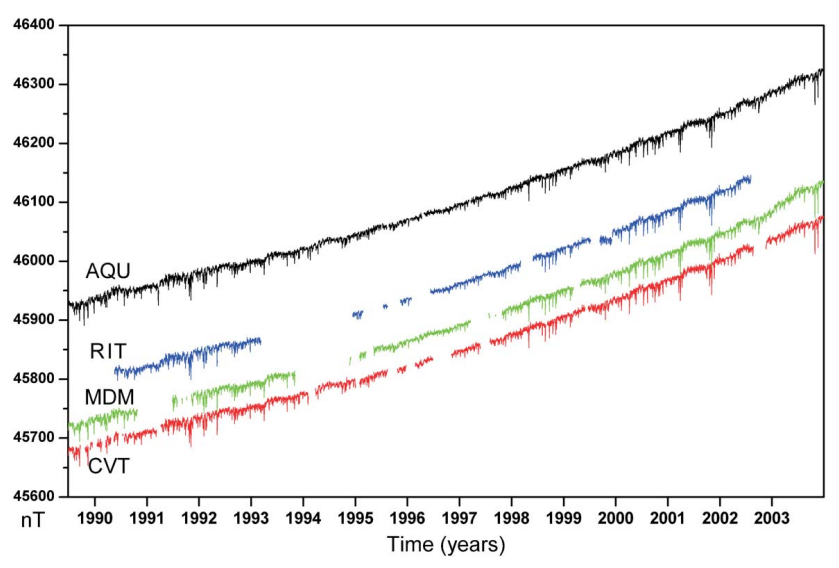

Fig. 2. Time variations of total magnetic field (F) at L'Aquila (AQU) and at tectonomagnetic stations (CVT, MDM, RIT) from July 1989 to 2003 .

earthquakes with $M d>=4.0$ occurred in the study area in 2002-2003 are listed.

More detailed information on the experimental equipment characteristics can be found in previous papers (Meloni et al., 2001, 2004).

\section{Data analysis}

\subsection{Magnetic observations}

The Earth's magnetic field variations have been collected since late 1989 in three sites in Central Italy, and at the national geomagnetic observatory of L'Aquila. Daily averages of the sampled datasets are shown in Fig. 2 (for station acronyms refer to Fig. 1). As known, solar cycles modulate the planetary magnetic activity which had a minimum during the time interval between 1993 and 1998. Planetary storms appear as high frequency behaviour in each curve. Last two years 2002 and 2003 of the presented data on which we focused our interest are shown on a wider time window for a better visualization in Fig. 3 .

In order to reduce contributions due to the external electric currents in the ionosphere and magnetosphere we applied a differentiation procedure between station pairs. Such

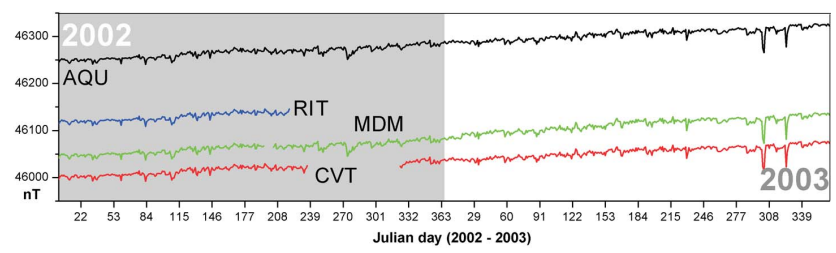

Fig. 3. Enlarged window of time variations of total magnetic field (F) at L'Aquila (AQU) and at tectonomagnetic stations (CVT, MDM, RIT) for the years 2002 and 2003.

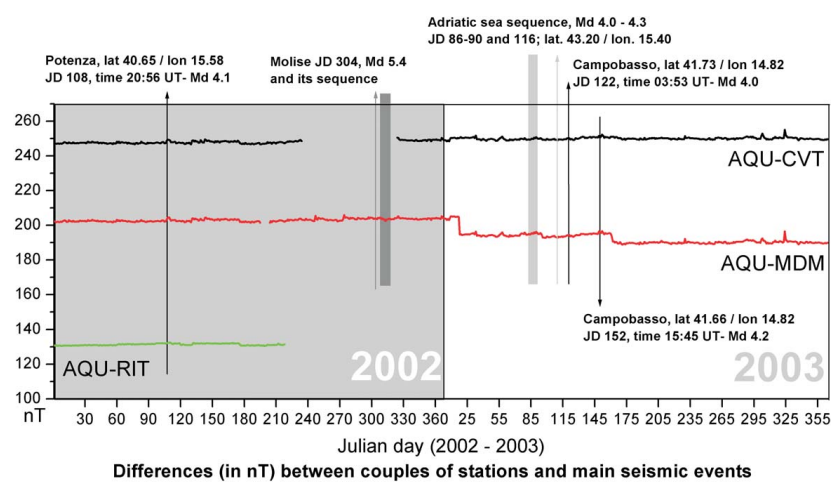

Fig. 4. Daily differences (in $\mathrm{nT}$ ) between couples of stations and main seismic events occurred in 2002 and 2003 in the study area. For further details on seismic events refer to Table 1.

method, consisting essentially in the computation of a pure difference between signal strengths recorded at each station with respect to a reference one (in our case L'Aquila), also eliminates the long term contribution (large part of the nonuniform secular variation) of internal origin, caused by the Earth's core electric currents. The remaining part is related to local changes in crustal magnetization, and possibly related to seismic and tectono-magnetic effects. Daily averages of differences of CVT, MDM, RIT and AQU datasets for 2002 and 2003 are shown in Fig. 4. Black lines indicate the occurrence of the most intense earthquakes occurred in the study area $(M d>=4.0)$, while grey bands indicate the occurrences of the Molise seismic sequence of October-November 2002 and the Adriatic sea sequence of March-April 2003 (as reported in Table 1).

Some moderate seismicity and three $M d>5$ events occurred in the study area during 2002 and 2003, but no clear evidence of possible correlations between magnetic data and seismic events were found. Two decreases of about $10 \mathrm{nT}$ and about $4 \mathrm{nT}$ were recorded in the difference AQU-MDM at the beginning and at mid 2003, respectively. Such decreases are persistent for the rest of the year and are not due, to our knowledge, to instrumental failures nor to man made interferences; these events need more investigation.

In Fig. 5, we show the results of wavelet analysis (Torrence and Compo, 1998) applied to the differences AQU-MDM, AQU-RIT and AQU-CVT for the whole available dataset; in particular we computed the dynamic power spectra by means of "Morlet" mother wavelet. It is evident that, as expected, 

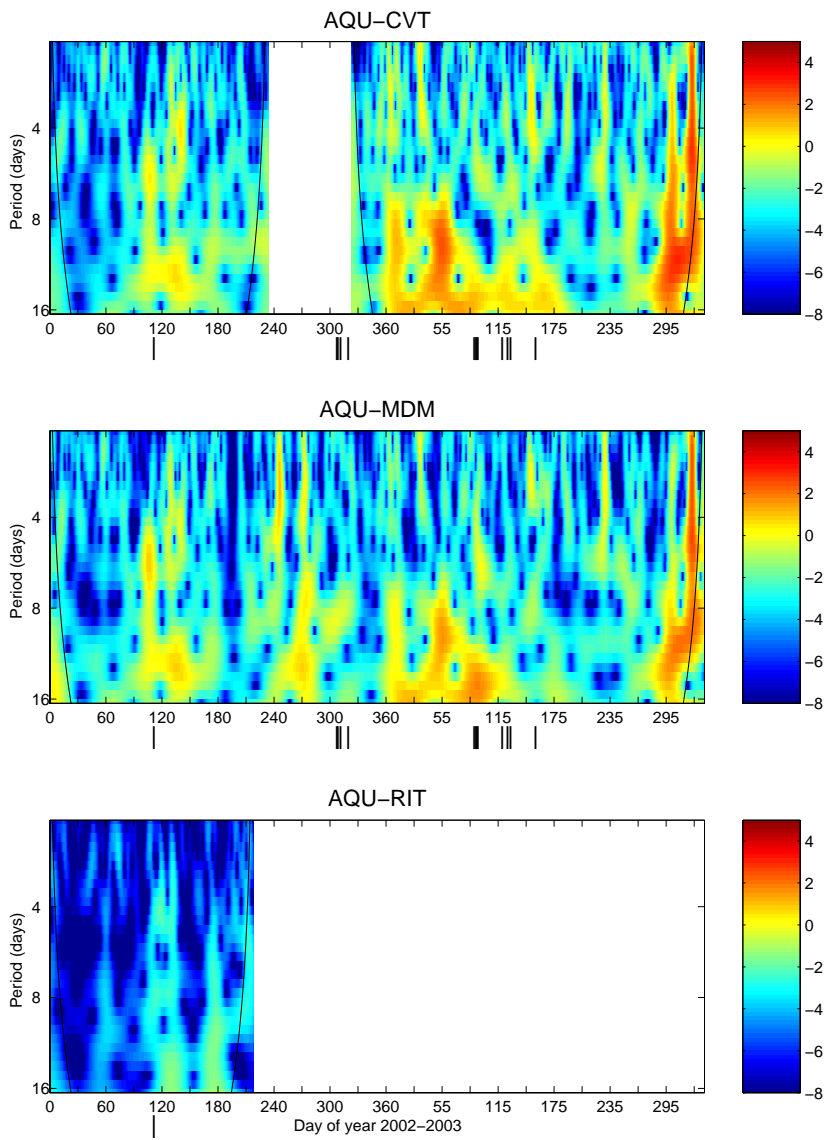

Fig. 5. Dynamic spectrum in logarithmic scale of the daily differences AQU-CVT, AQU-MDM and AQU-RIT for the years 20022003. Black curves indicate the "cone of influence", where edge effect becomes important. The lines in the lower border indicate the occurrence time of earthquakes $(M d>=4)$. Colour bars indicate the power density in $(\mathrm{nT})^{2} / \mathrm{Hz}$.

the power content is lower for the closest pair station AQURIT. An unusual power enhancement with period around 6 days occurs in the differences AQU-CVT and AQU-MDM in correspondence with the Potenza earthquake (18 April 2002). This seismic event, although just outside the network limits, actually occurred closer to CVT and MDM than to RIT and when the three stations were in operation. We note that during 17-21 April 2002 an intense geomagnetic storm, with Dst index reaching $-150 \mathrm{nT}$, occurred. When only two stations MDM and CVT were correctly working, a clear power enhancement is shown over a long period at the beginning of 2003. No strong magnetospheric origin perturbations are reported for this period and the time window of interest is very close to the Adriatic sea seismic sequence of the late March 2003.

\subsection{VLF observations}

Figure 6 shows the time variability of natural electromagnetic signals, along E-W direction, for the periods MarchSeptember 2001 and August 2002-March 2003; the arrows
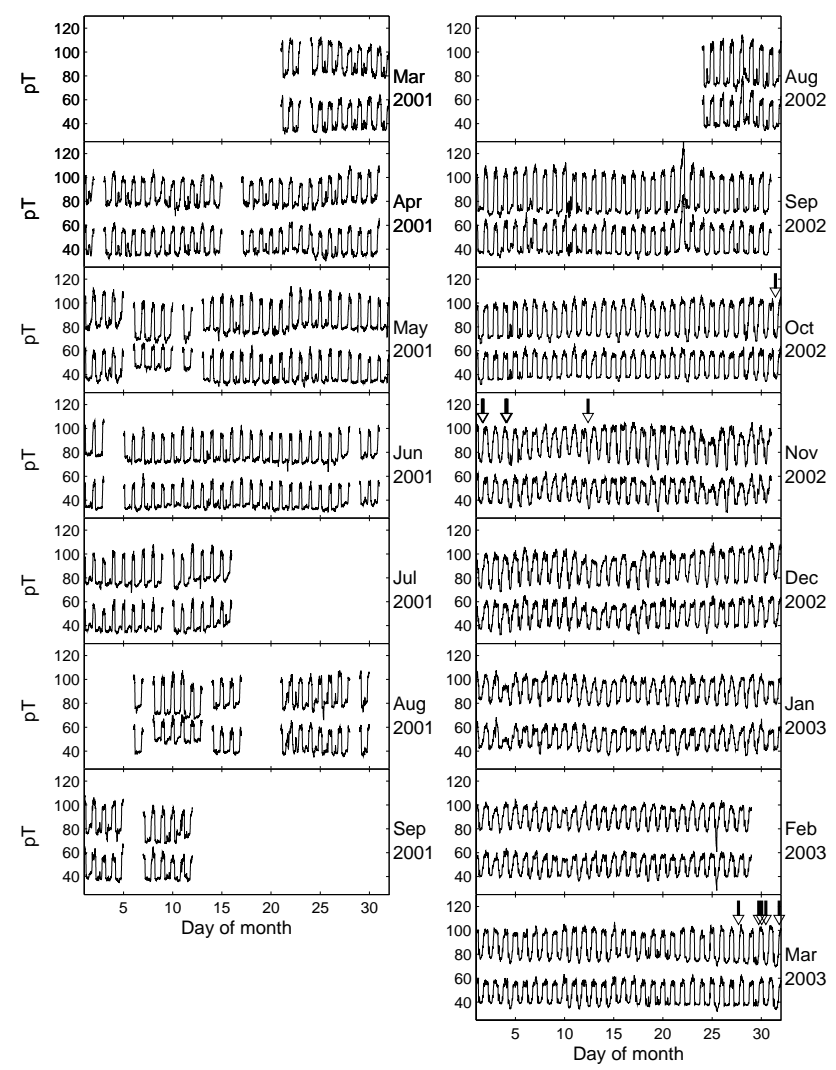

Fig. 6. VLF data (1 min averages) for the time periods MarchSeptember 2001 and September 2002-March 2003. The arrows indicate the occurrence time of earthquakes $(M d>=4)$. Upper curves show $40 \mathrm{kHz}$ data (upward shifted by $20 \mathrm{pT}$ ), lower curves show $20 \mathrm{kHz}$ data.

in the plots indicate the seismic events (see Table 1 for the 2002-2003 time period; no seismic events with $M d>=4.0$ occurred in 2001, Meloni et al., 2004). VLF data do not show any significant anomaly in correspondence to earthquakes; moreover, in the whole analyzed time series, no anomalous signal enhancement comparable to the one recorded in correspondence with the 1997 seismic events (Meloni et al., 2001) is present.

In monitoring the ionospheric characteristics that could be related in some way to tectonic events, useful parameters could be the nighttime and daytime levels of VLF signals as well as their difference, which is independent on possible changes of the data offsets. We computed these parameters considering as daytime and nighttime the 4-hour time intervals around local noon and midnight (i.e. 10:00-14:00 LT and 22:00-02:00 LT), respectively. Results, shown in Fig. 7 only for the $20 \mathrm{kHz}$ signals (the results for $40 \mathrm{kHz}$ are very similar), prove that in the two analyzed time periods the daytime and nighttime VLF levels and their difference do not exhibit clear irregularities in correspondence to the seismic events (indicated in the plot by the arrows). Rather, the daytime level during 2002-2003 shows some evidence for a periodic drop every 7 days (particularly evident around days 320 , 2002; 20 and 60, 2003), occurring on Tuesdays; this feature, 

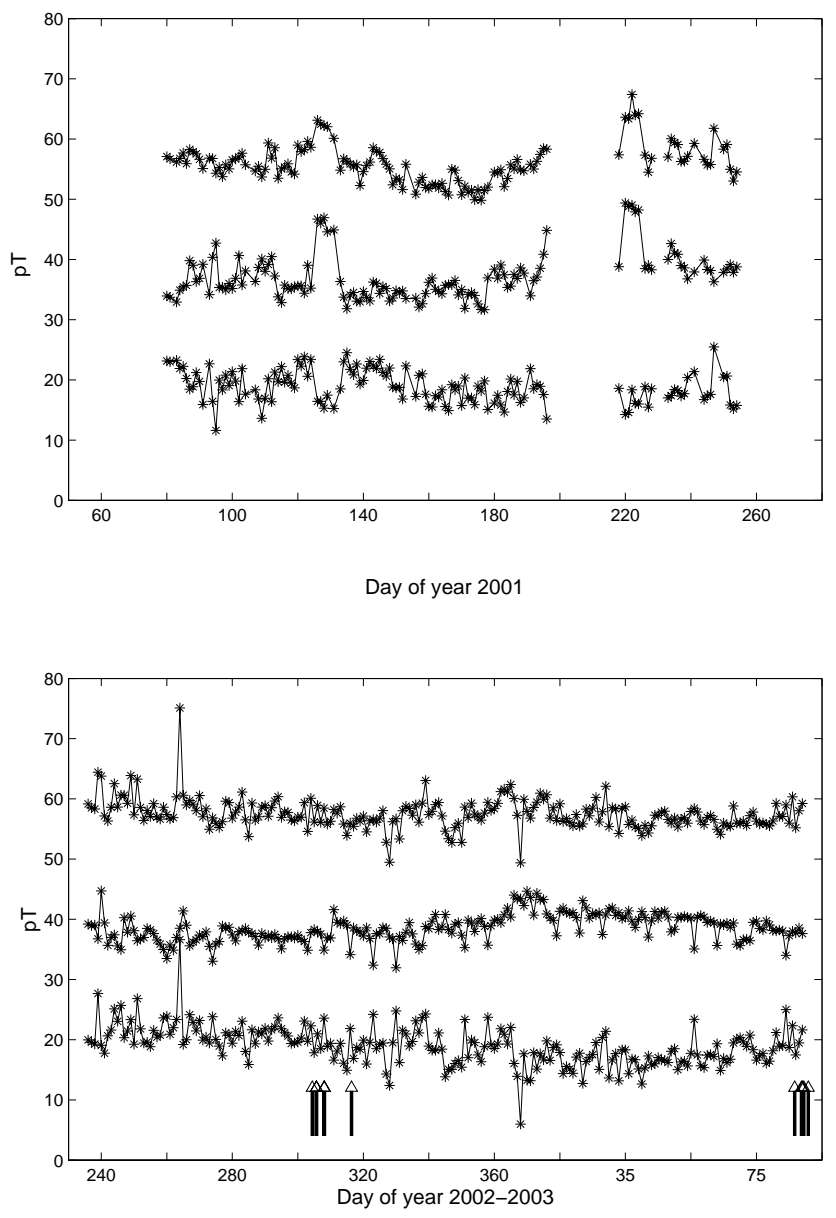

Fig. 7. From top: nighttime (22:00-02:00 LT) and daytime (10:0014:00 LT) levels of VLF $20 \mathrm{kHz}$ signals and their difference for the time periods March-September 2001 (upper box) and September 2002-March 2003 (lower box). The arrows indicate the occurrence time of earthquakes $(M d>=4)$.

clearly of artificial origin, needs a more detailed analysis.

We also calculated the morning and afternoon terminator time (TT), defined as the time of the minimum and of the maximum in the differentiated data, respectively; in order to remove high frequency variations and noise which gave rise to spurious minima and maxima, data have been previously averaged at $15 \mathrm{~min}$. The TT variation, during the analyzed time periods, is shown in Fig. 8. The expected TT seasonal variation, related to the change of sunrise and sunset times, clearly emerges. It is evident that the TT is better defined in morning than afternoon and this feature is due to the fact that the afternoon VLF level increase is very smooth, expecially during winter, while the morning decrease is more steep; on the contrary, Molchanov et al. (1998), who determined the TT from signal phase variations, found that results are more clear for afternoon TT than for morning TT. Also in this case no clear correspondence between TT anomalies and reported seismic events is found.

In Fig. 9 we show the VLF signals dynamic spectra for the time period September 2002-March 2003, when the data
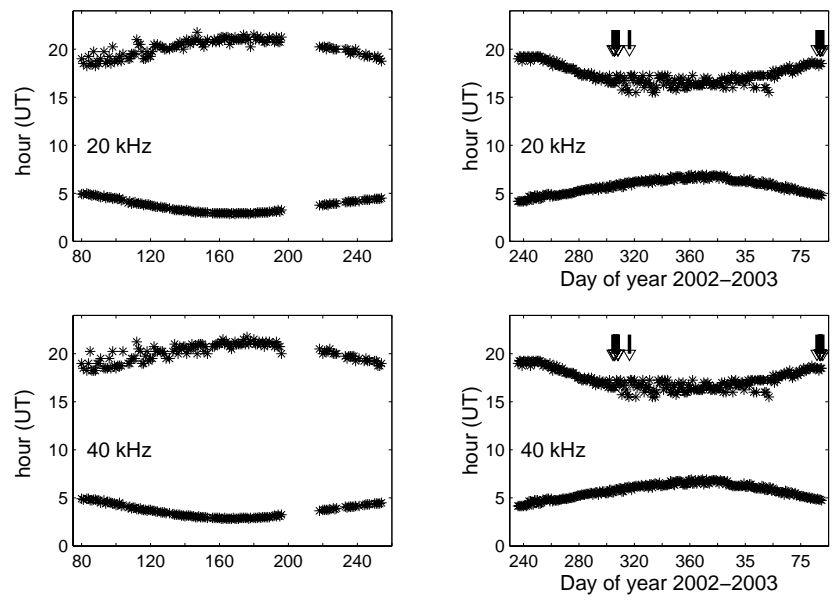

Day of year 2001

Fig. 8. Morning and afternoon terminator time for MarchSeptember 2001 (left) and September 2002-March 2003 (right). The arrows indicate the occurrence time of earthquakes $(M d>=4)$.

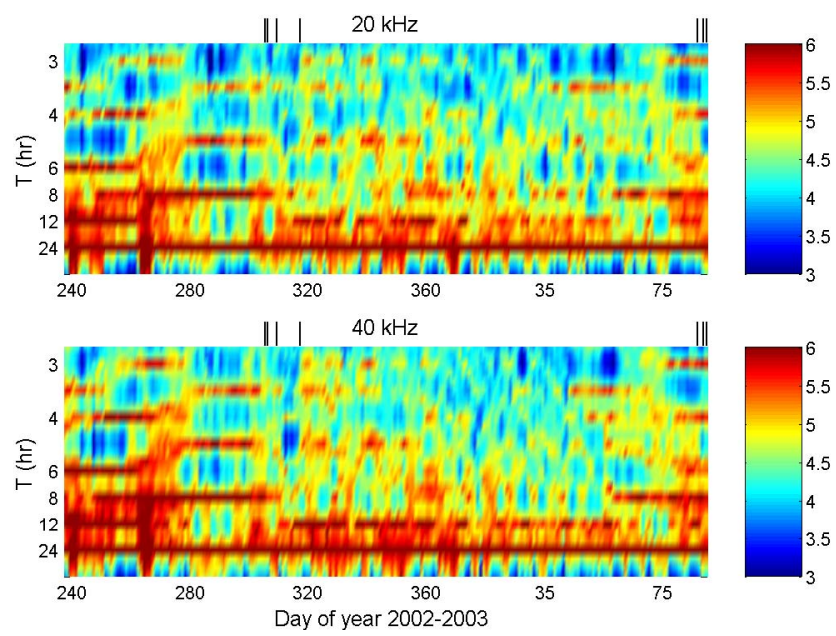

Fig. 9. Dynamic spectrum in logarithmic scale of the $20 \mathrm{kHz}$ and $40 \mathrm{kHz}$ VLF signals for the time period September 2002-March 2003. The lines in the upper border indicate the occurrence time of earthquakes $(M d>=4)$. Colour bars indicate the power density in $(\mathrm{pT})^{2} / \mathrm{Hz}$.

coverage is continuous; the spectra have been obtained from 3-days consecutive spectra, calculated with the maximum entropy method, with a step of 1 day. A very evident power enhancement corresponding to the 24-hour variation, together with its harmonics, is shown. It is interesting to note that the higher harmonics are not always present, and their relative amplitude changes with time. In particular, we note that around day 280,2002 , the odd harmonics emerge very clearly; they persist for more than 20 days and seem to disappear in correspondence to the Molise seismic sequence (days 304-316). 


\section{Conclusions}

In order to acquire a better knowledge of the natural tectonomagnetic and electromagnetic phenomena observed in Central Italy, seismomagnetic and VLF data were recorded and analysed in the search of possible correlation to seismic activity. No evidence of magnetic time variations of crustal origin in association to earthquake occurrences was clearly found. Wavelet analysis was applied to seismomagnetic signals in order to better characterize the behaviour of each station response, with hidden discontinuities and spikes into the signal. This analysis has shown the existence of some power enhancements in the dynamic spectra in correspondence of time periods of seismic activity. In particular, a power enhancement emerges in correspondence of the Potenza earthquake in April 2002. In the case of the Adriatic sequence, when no indication of unusual external magnetic perturbations is present in the data, a long duration power enhancement shows up at the beginning of 2003.

In the assessment of earthquake electromagnetic related phenomena, continuous VLF observation seems to have a promising role. In our case, VLF wave plots for 20 and $40 \mathrm{kHz}$ signal levels in their 1-min averages do not reveal significant variations comparable to those recorded in the 1997 event (Meloni et al., 2001). Data achieved in the following years have shown that evident variations are not frequently recorded at L'Aquila and moreover at the same time no other significant earthquakes were recorded. However, the connection between VLF signals perturbations and earthquake occurrence is reported in literature for events with $M d>5.5$. Statistics on data also showed that some ionospheric parameters help us to find some peculiarities which give a distinctive identity to the measurement point. More data are needed to reach convincing conclusions but continuous monitoring of tectonomagnetic and VLF integrated averages time variations will be continued in this area of Central Italy.

Edited by: P. F. Biagi

Reviewed by: two referees

\section{References}

Barr, R., Llanwyn Jones, D., and Rodger, C. J.: ELF and VLF radio waves, J. Atmos. Solar-Terr. Phys., 62, 1689-1718, 2000.

Daubechies, I.: Orthonormal Bases of Compactly Supported Wavelets, Comm. Pure Appl. Math., 41, 906-966, 1988.

Del Negro, C., and Currenti, G.: Volcanomagnetic signals associated with the 2001 flank eruption of Mt. Etna (Italy), Geophys. Res. Lett., 30, 1357-1361, 2003.

Gokhberg, M. B., Gufeld, I. L., Rozhnoy, A. A., Marenko, V. F., Yampolsky, V. S., and Ponomarev, E. A.: Study of seismic influence on the ionosphere by super long-wave probing of the Earth-ionosphere waveguide, Phys. Earth Planet. Inter., 57, 64 67, 1989.
Hayakawa, M. and Fujinawa, Y.: Electromagnetic Phenomena Related to earthquake Prediction, Terra Sci. Pub. Comp., Tokyo, 677 p., 1994.

Hayakawa, M. and Molchanov, O. A., (eds.): Seismo Electromagnetics: Lithosphere-Atmosphere-Ionosphere Coupling, TERRAPUB, 477 p., Tokyo, 2002.

Hayakawa, M., Molchanov, O. A., Ondoh, T., and Kaway, E.: The precursory signature effect of the Kobe earthquake in VLF subionospheric signal, J. Comm. Res. Lab., Tokyo, 43, 169-180, 1996 a.

Hayakawa, M., Molchanov, O. A., Ondoh, T., and Kaway, E.: Anomalies in the sub-ionospheric VLF signals for the 1995 Hyogo-ken Nanbu earthquake, J. Phys. Earth, 44, 413-418, 1996b.

INGV (Istituto Nazionale di Geofisica e Vulcanologia): Seismic Bulletin (Rome), 2004.

Johnston, M. J. S.: Review of electrical and magnetic fields accompanying seismic and volcanic activity, Surv. Geophys., 18, 441-475, 1997.

Johnston M.: Electromagnetic fields generated by earthquakes, in: International Handbook of Earthquake and Engineering Seismology, part A, edited by: Lee, W., Kanamori, H., Jennings, P., and Kisslinger, K., 621-634, Academic Press, 2002.

Meloni, A., Patella, D., Vallianatos, F., and Zolesi, B. (eds.): Magnetic, Electric and Electromagnetic Methods in Seismology and Volcanology, Chania Greece, Annali di Geofisica, 44, 2, 474 p., 2001.

Meloni, A., Di Mauro, D., Lepidi, S., Mele, G., and Palangio, P.: Tectonomagnetic and VLF electromagnetic signals in Central Italy, Annals of Geophysics, 47, 29-34, 2004.

Meyer, Y.: Wavelets: Algorithms and Applications, Society for Industrial and Applied Mathematics, Philadelphia, 13-31, 101105, 1993.

Molchanov, O. A. and Hayakawa, M.: Subionospheric VLF signal perturbations possibly related to earthquakes, J. Geophys. Res., 103, 17 489-17 504, 1998.

Molchanov, O. A., Hayakawa, M., Oudoh, T., and Kaway, E.: Precursory effects in the subionospheric VLF signals for the Kobe earthquake, Phys. Earth Planet. Inter., 105, 239-248, 1998.

Morgounov, V. A., Ondoh, T., and Nagai, S., Anomalous variation of VLF signals associated with strong earthquakes $(M>=7)$, in: Electromagnetic Phenomena Related to earthquake Prediction, edited by: Hayakawa, M. and Fujinawa, Y., Terra Sci. Pub. Comp., Tokyo, 409 p., 1994.

Nagao, T., Enomoto, Y., Fujinawa, Y., Hata, M., Hayakawa, M., Huang, Q., Izutsu, J. Kushida, Y., Maeda, K., Oike, K., Uyeda, S., and Yoshino, T.: Electromagnetic anomalies associated with 1995 Kobe earthquake, J. Geodyn., 33, 401-411, 2002.

Parrot, M.: Use of satellites to detect seismo-electromagnetic effects, Adv. Space Res., 15, 27-35, 1995.

Parrot, M. and Johnston, M.: Seismo-electromagnetic effects, Special Issues, Phys. Earth Planet. Int., 77, 1-137, 1993.

Rozhnoi, A., Solovieva, M. S., Molchanov, O. A., and Hayakawa, M.: Middle latitude LF $(40 \mathrm{kHz})$ phase variations associated with earthquakes for quiet and disturbed geomagnetic conditions, Phys. Chem. Earth, 29, 589-598, 2004.

Shvets, A. V., Hayakawa, M., Molchanov, O. A., and Ando, Y.: A study of ionospheric response to regional seismic activity by VLF radio sounding, Phys. Chem. Earth, 29, 627-637, 2004.

Torrence, C. and Compo, G. P.: A Practical Guide to Wavelet Analysis, Bulletin of the American Meteorological Society, 79, 6178, 1998 . 